\title{
Aggression and Peer Violence Manifestation in Youth Sport - The Case Study
}

\author{
Brigita Banjac \\ $\mathrm{PhD}$ candidate at Faculty of Sport and Physical Education \\ University of Novi Sad \\ 16 Lovćenska, 21000 Novi Sad \\ Serbia \\ Ivana M. Milovanović \\ Associate Professor at Faculty of Sport and Physical Education \\ University of Novi Sad \\ 16 Lovćenska, 21000 Novi Sad \\ Serbia \\ Radenko M. Matić* \\ Assistant Professor at Faculty of Sport and Physical Education \\ University of Novi Sad \\ 16 Lovćenska, 21000 Novi Sad \\ Serbia \\ Elisabetta Di Giovanni \\ Associate Professor at Department of Psychology \\ Educational Science and Human Movement \\ University of Palermo, Viale delle Scienze \\ Building 15, 90128 Palermo \\ Italy \\ Jovan Vuković \\ $\mathrm{PhD}$ candidate at Faculty of Sport and Physical Education \\ University of Novi Sad \\ 16 Lovćenska, 21000 Novi Sad \\ Serbia
}

\begin{abstract}
This study was designed to detect aggression and peer violence manifestation forms in youth sports in Subotica. The sample consisted of athletes $(N=255)$, aged between 11 and 18 years. Besides presenting descriptive statistics, the Mann-Whitney $U$ test was used to assess the differences in variables (gender, school age, training years, sport type) among the forms of violence that can occur and among the ones that do occur. The results indicate the presence of aggression and violence. The most frequent place is in the dressing room, and the more common period is after or during training and while traveling to competitions, sports camps, etc. The study indicates significant differences in sexual violence between primary and secondary school-age children. Moreover, physical and psychological violence is significantly dominant in collective sports compared to the individual ones. Recognizing the presence of these phenomena is the first step toward reducing their potential negative outcomes.
\end{abstract}

Keywords: child, youth, aggression, peer violence, sport, Subotica.

\section{Introduction}

\subsection{Aggression and violence as latent social phenomenon}

The concepts of aggression and violence are little understood phenomena because their roots are much more profound than their manifestations and consequences (Milovanović, Milošević, Maksimović, Korovljev, \& Drid, 2019). Throughout the research paper, these concepts will be interpreted in the field of social sciences (as forms of deviant behavior).

* CONTACT: Radenko M. Matic, e-mail: radenkomatic@uns.ac.rs, Faculty of Sport and Physical Education, Sport Management, University of Novi Sad, Lovcenska 16, Novi Sad 21000, Serbia. 
Aggression's meaning is related to the "behavior that is intended to harm another person who is motivated to avoid that harm" (Allen \& Anderson, 2017; Anderson \& Bushman, 2002; Bushman \& Huesmann, 2010). Accordingly, accidental harm is not classified because of the absence of intention (Anderson \& Bushman, 2002). In addition, aggression as a phenomenon can appear in many forms (minor, serious, or severe acts) according to their multidimensional nature. It is also frequently used for explaining personality and attitudes, besides characterizing a person's behavior (Liu, 2004).

Some of the aggression classifications are: instrumental and hostile; positive and negative; male and female (Liu, 2004); reactive and proactive; direct and indirect; displaced and triggered; overt and covert; impulsive and premeditated; legitimate and illegitimate; personal and situational; physical (e.g., punching, kicking), verbal (e.g., calling, swearing), or relational (e.g., damaging social relationship, exclude peers) (Allen \& Anderson, 2017; Bushman \& Huesmann, 2010).

Aggression behavior is an outcome of internal and external stimuli. Causes could be social or biological (Liu, 2004). In addition, important predictors for aggressiveness and antisocial tendencies are morality (accept norms and rules) (Gentile et al., 2019; Živković, Stamenković, \& Marković, 2013) and the mechanism of prejudice (Gentile et al., 2019).

Even though that aggression and violence terms usually appear to be synonymous and overlap in everyday meaning, they differ in intensity and destruction. To understand these behaviors, they have to be seen on a continuum of severity (Huesmann \& Taylor, 2006). Aggression is more complex and contains violence, but conversely, it is not the case (Allen \& Anderson, 2017; Anderson \& Bushman, 2002).

Violence as a subset of aggression (Allen \& Anderson, 2017) is often described as "a form of aggressive behavior, in which a conscious effort is made to cause a downfall or injury" (Tripković, 2007) or "an extreme form of aggression that has severe physical harm (e.g., serious injury or death) as it goal" (Anderson \& Bushman, 2002; Bushman \& Huesmann, 2010). From the sociological perspective, it is very broadly understood as anything that forcibly hinders and limits the realization and development of positive human resources (Radenović, 2012). The most investigated forms are direct or interpersonal violence (Milovanović et al., 2019a), but they can appear between peers, family, or even in sport (Živković et al., 2013).

The negative consequences of aggression and violence are well documented in the literature. It could lead to sociopsychological problems (child turns in oneself or lose self-confidence) (Milovanović et al., 2019), hurt individual's feelings (Milovanović, Roklicer, \& Drid, 2019), physical injury, damaged social relationships (Allen \&Anderson, 2017); or even fatal and irreparable damages in adolescents (Park, Chiu, \& Won, 2017).

There is no consensual definition and classification for these social phenomena because they are widespread, multidimensional, socially constructed (Milovanović, Gentile, et al., 2020; Radenović, 2012, Bojanić et al., 2015), and related to many sciences: sociology, psychology, politics, criminology, etc. (Milovanović et al., 2019a). Many theories tried to integrate them into a framework (e.g., Cognitive Neoassociation Theory, Social Learning Theory, Script Theory, Excitation Transfer Theory, Social Interaction Theory, The General Aggression Model, etc.) (Anderson \& Bushman, 2002). The measured frequency of aggression and violence varies from sample to sample, which indicates the presence of different research methods and criteria (Popadić, 2009). It is clear, if they do not have a universal definition of these social phenomena, the used measurements will slightly differ.

Although these behaviors are threatened as destructive features with negative consequences, a distinction must be made between violence (as an independent motive to hurt somebody) or force as a reaction to vulnerability. In the second case, violence and aggression are necessary, inevitable, and desirable (Radenović, 2012; Tripković, 2007) behaviors; thus, they can protect the individual (Liu, 2004).

\subsection{Aggression and violence in the sports environment}

The sports environment could represent a natural setting for the interactions between peers and a good place to explore how aggressive and violent behavior develops. This topic draws research attention from the ' $80 \mathrm{~s}$ (Milovanović et al., 2019b; Milovanović et al., 2020). First, it has to analyze the individual behavior within the group to understand intergroup violence (De Wall, Anderson, \& Bushman, 2011).

Sport is a cultural phenomenon, and it has a different meaning for everyone. However, it matters to every child (with their parents) because it is generally seen as a favorite extracurricular activity (regardless of parent's educational and material status (Milovanović et al., 2019)), with an opportunity of experiencing group interaction and developing group behaviors (Milovanović, Roklicer, et al., 2020). Children who play sports activities enrich with happiness; therefore, they love to play and enjoy the time spending these activities as they say: "I really get load of enjoyment out of it; it is not boring, it is fun, etc." (Bačanac, Petrović, \& Manojlović, 2009; Brackenridge, Fasting, Kirby, \& Leahy, 2010; Collins, Cromartie, Butler, \& Bae, 2018; Živković et al., 2013). 
The sport environment plays an important role in transmitting and adopting knowledge, norms, values (Wankel \& Berger, 1990), developing healthy habits and behavior (Milovanović et al., 2019b; Park et al., 2017; Steptoe \& Butler, 1996). Furthermore, sports activities have the potential to acquire the most desirable values: personality development; prosocial attitude and behavior (e.g., sharing, helping, donating, cooperating with others), cohesion between athletes; socialization; self-esteem; self-concept; tolerance to others; peer acceptance (Bailey, 2006; Collins et al., 2018; Milovanović et al., 2020; Park et al., 2017); positive character. These could be defensive mechanisms for aggression and violence (Milovanović et al., 2019a; Milovanović et al., 2019b; Wang et al., 2015).

The mechanism, how children can copy the aggressive attitude or prosocial behavior from coaches, parents, careers, or any significant figures in their lives threatened as a role model is described in the social learning theory (Bandura, 1973). It explains how people learn (or imitate) to behave in everyday life by observing their model acts (Bačanac et al., 2009; Huesmann \& Taylor, 2006; Milovanović, et al., 2020). This framework neglects the factors that cause these behaviors and are independent of one's learning history (De Wall et al., 2011).

Another way to copy or stimulate assaultive acts is by watching television, film, or playing games that demonstrate aggressive behaviors (Huesmann \& Taylor, 2006).

In essence, sport is not a priori good or bad. It can have an extensive scope of potential (both positive and negative) outcomes (Wankel \& Berger, 1990). Accordingly, there are contradictory claims about sports activities' effect, so the sport's characteristics must be considered. There is a contrasting view of the effect of sport (decrease or increase) on aggression. Sport is usually interpreted as a positive social phenomenon (Milovanović, Matić, et al., 2020) with multiple benefits and outcomes in the physical, lifestyle, social, affective, and cognitive domain (Bačanac et al., 2009; Bailey, 2006). Moreover, they maintain self-esteem (Richman \& Shaffer, 2000), well-being (Steptoe \& Butler, 1996), health, optimism, confidence, self-concept, humor, internal capability, control for environmental crisis (Koo \& Lee, 2014), social integration (Wankel \& Berger, 1990) and cohesion, education with personal and social development (Brackenridge et al., 2010; Wankel \& Berger, 1990). On the other hand, the negative outcomes are followed by the nature of the sport. Declaratively emphasizing competitions and victory lead to pressure, stress, and frustration, which can cause aggressive and violent behavior (Milovanović et al., 2019b; Park et al., 2017; Živković et al., 2013) and affect the psycho-physical stability of the athletes and group dynamic (Milovanović et al., 2019a, Milovanović et al., 2019b).

Furthermore, it is crucial to practice sport by the child's intrinsic motivation (to be satisfied and want to practice) and not driven by the parent's dream. Otherwise, this training experience can lead to frustration and aggression (Bačanac et al., 2009). In addition, to understand the athlete behavior, it is worth mentioning two phenomena, which can be related to aggression and violence: self-esteem and perfectionism. Self-esteem improves the ability to monitor better their self-performance compared to others (Milovanović et al., 2019b); while perfectionism can be treated as a "double-edged sword": as an adaptive trait, which can have benefits (striving, focusing on effort); or as a maladaptive trait, which leads to difficulties, costs and risks (unrealistic aims, high focus on winning, frustration, stress or aggression) (Bojanić, Šakan, \& Nedeljković, 2018; Stoeber, 2014). The orientation and pressure of winning can be counterproductive, and change the assertive behavior to violent (assertive behavior: believing in the team; instrumental aggression: fair play game; hostile aggression: victory at all cost; violent behavior: hurting the opponent) (Živković et al., 2013).

Besides that sport is a desirable environment for aggression and violence prevention, these behaviors appear in sports activities, as shown in earlier researches (Brackenridge et al., 2010; Milovanović, et al., 2020a; Milovanović et al., 2020b; Milovanović et al., 2019a; Milovanović et al., 2019b; Park et al., 2017; Živković et al., 2013).

\subsection{The importance of researching these phenomena in contemporary society}

Aggression and violence are a symbol of society and part of everyday life (Živković et al., 2013). They are as old as human beings, society, and culture; likewise, it is neither accidental nor temporary (Tripković, 2007). Our ancient ancestors used aggression for the survival of the group. Conversely, as the culture developed, this behavior became less adaptive and caused more problems than it solves (De Wall et al., 2011). Culture has the potential power to affect these behaviors' development (Wang et al., 2015). Every culture adapted the sport accordingly with its specificity, emphasizing different emphases and meaning, which resulted in how the same sport is played a little bit differently (Wankel \& Berger, 1990).

There are multiple reasons that investigation of aggression and violence is one of the most important topics in contemporary society; partly because of their increased frequency (Milovanović et al., 2019b), and that it became more massive, destructive, and efficient (Tripković, 2007; Radenović, 2012). Children and youth in everyday life within the sport are generally exposed to aggression, violence, and social exclusion, especially minority groups (functionally disabled, ethnic minority, lower social classes) (Milovanović et al., 2020a; Milovanović et al., 2019b), but this does not mean that they are limited to any particular country, sport, group, position, or any type of perpetrator person (Williams, 2011). 
The main problem with these prevalent and destructive behaviors is that they are covered, often remain hidden (Williams, 2011), and not easily recognizable. Thus, it is complex to measure their full extent, nature, and type. So, ideally, it must be measured for a more extended period than once with a survey.

There is no universal agreement about the most effective method for measuring and preventing aggression and violence either in or beyond the sports domain. However, education and awareness play an important role in recognizing, preventing, dealing, and appropriately responding to these social phenomena (Brackenridge et al., 2010). In addition, important strategies are to understand these behaviors, promote acceptance of diversity (Milovanović, et al., 2020b), and stimulation consciousness towards this issue among athletes (Milovanović et al., 2020a), that in the end children would be oriented to solve conflict situations without harming others (Gentile et al., 2019).

A good start against these behaviors is identifying their presence and nature. Therefore, this research aimed to examine the presence and the extent to which they are exposed to these behaviors and manifestation forms of aggression and peer violence in youth sport. We hypothesized that there is some type of violence among athletes in Subotica.

\section{Methods}

\subsection{Participants}

The target population consisted of children $(\mathrm{N}=255)$ aged between 11 and 18 years in this study, attending primary or secondary school, from Serbia in Subotica city and nearby towns, suburbs, and villages. They were athletes (children who systematically and regularly train sport) with different years of sports experiences from various sport types, including football, swimming, volleyball, dance, artistic gymnastics, cycling, basketball, hockey, tennis, figure skating, handball, karate, and kickboxing. The gender structure is mainly equal (131 boys and 124 girls), as seen in Table 1, with other respondent socio-demographic characteristics.

\subsection{Measurements}

Data were collected via questionnaire papers. The instrument consisted of two segments: socio-demographic and peer violence (forms and types). The first part contained variables such as gender, age, location, fathers' and mothers' education, number of children in the family, sport, and previous sports experience. The second part included questions about: a) the occurrence of peer violence in trained sport, b) the frequency of the peer violence among athletes, c) the time when (before, during, or after training; before, during, or after competition; during trips and sports camp) and the location where (gym, dressing room, training, and bathroom area) violence occur, c) forms of violence (physical, psychological and sexual). The survey was constructed by the authors of the research, which was used in earlier studies (Milovanović et al., 2020b). The participants' answers were measured on a fivepoint scale, from completely disagreeing to completely agree. They could also identify the forms of peer violence that can occur based on their beliefs, and the most occurred typed they experienced or seen in their sport, as shown in Table 2. The respondents' answers were anonymous and confidential.

\subsection{Procedures}

The research has a cross-sectional design. The study was realized from June till September 2020 in Subotica. Coaches, trainers, and even parents have surveyed children in sports clubs or home environments. The authors explained the basic instructions about the questionnaire (like answering honestly and independently) and the used terminology (such as violence or aggression). Each participant voluntarily agreed to be involved in this research. The research was approved by Faculty of Sport and Physical Education Ethics committee, with the official number: 46-11-07/2020-1.

\subsection{Data analysis}

Descriptive characteristics were calculated for the samples' socio-demographic characteristics and the occurrence of peer violence in sport reported by the participants. For testing our hypothesis about the manifestation of aggression and peer violence, the differences in the variables were examined with the nonparametric replacement of the t-test: Mann-Whitney U test. Data analysis was conducted through the program IBM SPSS Statistics (Statistical Package for the Social Sciences 25.0), where statistical significance was set at $\mathrm{p}<0.05$.

\section{Results}

\subsection{Descriptive characteristics}

Detailed descriptive statistics about the respondents' socio-demographic characteristics are presented in Table 1. The gender and the age (attending primary or secondary school) structure is mainly equally represented in this sample. The majority lived in town or city, which was expected according to the aim of this research. Over half of the surveyed children had one or more siblings. In addition, the individual and collective sport types are presented 
equally, in which the largest percentage of trained sports activities were football, swimming, volleyball, and dance. Moreover, half of the athletes have a training history between five and ten years.

Table 1. Descriptive Statistics for the Samples' Socio-demographic Characteristics

\begin{tabular}{|c|c|c|}
\hline Variable & $\mathrm{N}$ & $\%$ \\
\hline \multicolumn{3}{|c|}{ Gender } \\
\hline Female & 131 & 51.4 \\
\hline Male & 124 & 48.6 \\
\hline \multicolumn{3}{|c|}{ Age } \\
\hline Primary school (11-14 years of age) & 117 & 45.9 \\
\hline Secondary school (15-18 years of age) & 138 & 54.1 \\
\hline \multicolumn{3}{|c|}{ Location } \\
\hline Village or Suburb & 20 & 7.9 \\
\hline Town or City & 234 & 92.1 \\
\hline \multicolumn{3}{|c|}{ Father's education } \\
\hline Primary education & 6 & 2.5 \\
\hline Secondary education & 135 & 56.7 \\
\hline College education & 37 & 15.5 \\
\hline Higher education & 60 & 25.2 \\
\hline \multicolumn{3}{|c|}{ Mother's education } \\
\hline Primary education & 9 & 3.8 \\
\hline Secondary education & 105 & 43.9 \\
\hline College education & 42 & 17.6 \\
\hline Higher education & 83 & 34.7 \\
\hline \multicolumn{3}{|c|}{ Number of children in the family } \\
\hline 1 child & 38 & 15 \\
\hline 2 children & 158 & 62.5 \\
\hline 3 children & 46 & 18.2 \\
\hline 4 children & 7 & 2.8 \\
\hline 5 or more children & 4 & 1.6 \\
\hline \multicolumn{3}{|c|}{ Sport } \\
\hline Football & 90 & 35.3 \\
\hline Swimming & 41 & 16.1 \\
\hline Volleyball & 36 & 14.1 \\
\hline Dance (Folk Dance, Modern Jazz Dance, Ballet) & 32 & 12.5 \\
\hline Artistic Gymnastics & 22 & 8.6 \\
\hline Water polo & 12 & 4.7 \\
\hline Cycling & 6 & 2.4 \\
\hline Basketball & 6 & 2.4 \\
\hline Hockey & 5 & 2.0 \\
\hline Tennis & 1 & 0.4 \\
\hline Figure skating & 1 & 0.4 \\
\hline Handball & 1 & 0.4 \\
\hline Karate & 1 & 0.4 \\
\hline Kickbox & 1 & 0.4 \\
\hline \multicolumn{3}{|c|}{ Sports experience } \\
\hline 1 year & 6 & 2.4 \\
\hline $1-5$ years & 69 & 27.2 \\
\hline $5-10$ years & 128 & 50.4 \\
\hline Over 10 years & 51 & 20.1 \\
\hline
\end{tabular}


Table 2 presents the descriptive statistics of peer violence in sport. It is interesting to note that over $70 \%$ of the respondents believe that their sport is free from violence. On the other hand, when they were asked about the frequency of peer violence, it is evident that the most common answer (over 70\%) was "very often" or "quite often". Analyzed together, it can point out the presence of aggression and violence among children involved in sport. These results support the approach that maltreatment and violence of athletes or children can be the outcome of the ethnic culture, gender, social or economic discrimination (Brackenridge et al., 2010).

Table 2. Number and Frequency of Violence in Sport Based on the Participants' Answers

\begin{tabular}{|c|c|c|c|}
\hline & Variable & $\mathrm{N}$ & $\%$ \\
\hline \multicolumn{4}{|c|}{ Is there violence in the sport you practice? } \\
\hline Yes & & 72 & 28.6 \\
\hline No & & 180 & 71.4 \\
\hline \multicolumn{4}{|c|}{ How often does violence in your sport occur among children? } \\
\hline Very often & & 144 & 57.1 \\
\hline Quite often & & 62 & 24.6 \\
\hline Sometimes & & 41 & 16.3 \\
\hline Rarely & & 4 & 1.6 \\
\hline Almost never & & 1 & 0.4 \\
\hline
\end{tabular}

The most frequent time of violent appearance is after training (19.1\%), as shown in Table 3. Thus, it is not surprising that almost every third athlete reported the dressing room for the most common place. Moreover, while they are traveling to competitions, sports camps, etc. (16.6\%) and the time during training (15.9\%) is also the highly-rated time for peer violence appearance. The data contributes to the assumption that children involved in games, sport, or competitions often put all energy into the activity, with many emotions. Their effort to play well usually leads to a higher level of adrenalin, which can be positive, that improves the performance of the athletes; or negative, which leads to behavior to win for all cost. In both cases, the accumulated adrenalin does not disappear with the end of the training or competition, and the athlete's reactions will be much more powerful than before the sports activity. For example, a child will be much more aggressive and violent if their teammates do not exercise as better as their expectation was or as good as others. Furthermore, it is also noticeable that psychological (roughly 40\%) and physical violence (around 30\%) are the most predominant type of violence among athletes. At the territory of Vojvodina (including Subotica), a similar conclusion was reached by Milovanović et al. (2020b).

Table 3. Descriptive Statistics of Peer Violence Relying on the Respondents (\%)

\begin{tabular}{|c|c|c|c|c|c|}
\hline Variable & $\begin{array}{c}\text { I completely } \\
\text { disagree }\end{array}$ & I disagree & I am neutral & I agree & $\begin{array}{c}\text { I completely } \\
\text { agree }\end{array}$ \\
\hline \multicolumn{6}{|c|}{ When does violence among children occur? } \\
\hline Before training & 50.4 & 22.0 & 14.4 & 10.0 & 3.2 \\
\hline During training & 50.6 & 20.2 & 13.4 & 11.9 & 4.0 \\
\hline After training & 44.0 & 21.8 & 15.1 & 15.5 & 3.6 \\
\hline Before competition & 52.6 & 21.9 & 18.7 & 5.6 & 1.2 \\
\hline During competition & 48.6 & 18.2 & 18.2 & 11.1 & 4.0 \\
\hline After competition & 49.2 & 21.6 & 17.6 & 7.6 & 4.0 \\
\hline $\begin{array}{l}\text { While travelling to competitions, } \\
\text { sports camps, etc. }\end{array}$ & 49.8 & 19.0 & 14.6 & 12.6 & 4.0 \\
\hline In sports camps & 51.0 & 15.0 & 19.8 & 10.3 & 4.0 \\
\hline \multicolumn{6}{|c|}{ Where does violence among children occur? } \\
\hline In the gym & 53.6 & 17.9 & 15.9 & 10.7 & 2.0 \\
\hline In the dressing room & 42.9 & 15.0 & 14.2 & 21.7 & 6.3 \\
\hline In the training area & 52.2 & 19.5 & 16.3 & 9.6 & 2.4 \\
\hline In the bathroom/toilet area & 57.3 & 17.8 & 14.6 & 8.3 & 2.0 \\
\hline \multicolumn{6}{|c|}{ Forms of violence that can occur (in theory) } \\
\hline Physical violence & 28.5 & 13.8 & 20.9 & 23.7 & 13 \\
\hline Psychological violence & 17.7 & 14.6 & 18.1 & 31.1 & 18.5 \\
\hline Sexual violence & 56.9 & 16.6 & 15.0 & 7.5 & 4.0 \\
\hline
\end{tabular}




\begin{tabular}{lcccrr}
\hline \multicolumn{7}{c}{ Most common forms of violence that have occurred (in practice) } \\
\hline Physical violence & 34.4 & 15.4 & 20.9 & 20.2 & 9.1 \\
Psychological violence & 25.7 & 13.0 & 19.0 & 22.9 & 19.4 \\
Sexual violence & 70.6 & 11.1 & 15.5 & 2.8 & 0 \\
\hline
\end{tabular}

\subsection{Differences among manifestation forms of aggression and peer violence}

The Mann-Whitney $\mathrm{U}$ test findings are reported in Table 4, which was used to determine the differences in variables (gender, school age, training years, sport type) among the forms that can occur (in theory) and among the most frequent forms (in practice) of violence. Results indicate a higher (but not statistically significant) perception of physical and sexual violence in theory and physical violence in practice among boys compared to girls. Older school-age is a more characteristic period for any type of violence than younger school age based on the results. The only significant difference is observed for sexual violence between these ages, with higher results for the older peers $(\mathrm{U}=6882.5, \mathrm{p}=0.031)$. Furthermore, significant differences are observed in physical $(\mathrm{U}=6166, \mathrm{p}=0.004)$ and psychological $(\mathrm{U}=6692.5, \mathrm{p}=0.044)$ violence in theory; and in physical $(\mathrm{U}=5577, \mathrm{p}=0.000)$ and psychological $(\mathrm{U}=6557, \mathrm{p}=0.030)$ violence in practice, with higher results in both cases for the collective compared to the individuals' sports.

\section{Table 4. Results of Mann-Whitney U Test Among Variables in the Forms of Violence}

\begin{tabular}{|c|c|c|c|c|c|c|}
\hline \multirow[t]{2}{*}{ Variables } & \multicolumn{3}{|c|}{$\begin{array}{l}\text { Forms of violence that can occur } \\
\text { (mean rank) }\end{array}$} & \multicolumn{3}{|c|}{$\begin{array}{l}\text { Forms of violence that occurred most } \\
\text { frequently } \\
\text { (mean rank) }\end{array}$} \\
\hline & $\begin{array}{l}\text { Physical } \\
\text { violence }\end{array}$ & $\begin{array}{l}\begin{array}{l}\text { Psychological } \\
\text { violence }\end{array} \\
\end{array}$ & $\begin{array}{c}\text { Sexual } \\
\text { violence }\end{array}$ & $\begin{array}{l}\text { Physical } \\
\text { violence }\end{array}$ & $\begin{array}{l}\text { Psychological } \\
\text { violence }\end{array}$ & $\begin{array}{c}\text { Sexual } \\
\text { violence }\end{array}$ \\
\hline Boys & 131.83 & 127.06 & 130.57 & 133.36 & 123.98 & 125.47 \\
\hline Girls & 121.90 & 127.97 & 123.23 & 120.28 & 130.20 & 127.58 \\
\hline Younger school age & 120.61 & 125.17 & 120.04 & 122.28 & 124.24 & 117.85 \\
\hline Older school age & 132.32 & 129.43 & 132.80 & 130.93 & 129.30 & 133.76* \\
\hline $1-5$ years of training & 128.93 & 125.98 & 123.82 & 137.09 & 132.59 & 126.12 \\
\hline $\begin{array}{l}5 \text { or more years of } \\
\text { training }\end{array}$ & 125.49 & 127.42 & 127.61 & 122.10 & 123.97 & 125.95 \\
\hline Individual sport & 111.72 & 116.74 & 124.87 & 106.11 & 115.45 & 121.52 \\
\hline Collective sport & $137.84 *$ & 135.08* & 128.51 & $141.82 *$ & 135.20* & 130.05 \\
\hline
\end{tabular}

*p $<0.05$

\section{Discussion}

The current research paper investigated the presence and manifestation forms of aggression and peer violence among athletes aged 11-18 years old. The field research was conducted in sports clubs in Subotica. The conducted questionnaire consisted of two segments: socio-demographic characteristics and peer violence (forms and types). We hypothesized that there is an existence at some level of aggression and peer violence among athletes.

Sport, as an environment and favorite extracurricular activity, can have both positive and negative outcomes (including aggression and violence) (Wankel \& Berger, 1990). It has the power to affect individuals' health physically, mentally, and emotionally (Collins et al., 2018); be a socialization canal; filter out aggression; maintain prosocial behavior (Milovanović et al., 2020b), which can indirectly counteract with the effect of aggression (Wang et al., 2015); improve positivity, better problem and, conflict solving (Wankel \& Berger, 1990); self-esteem (Richman \& Shaffer, 2000); group cohesion between athletes (Milovanović et. al., 2020a); and reduce anxiety and depression (Wankel \& Berger, 1990). Although, from their nature, the importance of winning at the competitions can redound aggression and violent behavior (Milovanović et al., 2020b), especially when the expectations of parents, coaches, or athletes do not reflect on the reality (Wankel \& Berger, 1990). There is evidence that athletes' have lower levels of aggression than students because they have an opportunity to decrease their stress levels through sports activities (Milovanović, Roklicer, et al., 2020).

In this sample, children and youth on the question, "Is there violence in the sport you practice?" in the minority $(\mathrm{N}=72,28.6 \%)$ answered with a "yes" response. Although, at the next question, "How often does violence in your sport occur?" if the answers are collected, they 206 circled "quite often" $(\mathrm{N}=62,24.6 \%)$ and "very often" $(\mathrm{N}=144$, $57.1 \%)$. 
The detected contradictory claims about the presence and frequency of aggression and violence follow the theory that children often answer based on the premise that showing aggression is wrong, determined as socially inappropriate behavior, even if it is the case (Milovanović, Gentile, et al., 2020).

One of the possible reasons for facing deviant behaviors in the domain of sports activities could be the environment (including coaches' and parents' actions), which can also determine the experience (positive or negative) of athletes' sport participation (Bailey, 2006; Biddle, 1995; Wankel \& Berger, 1990). Children often imitate the observed behaviors (Huesmann \& Taylor, 2006). Thus, coaches and parents with their norms and standards influence the most athletes' behavior (Bačanac et al., 2009; Gentile et al., 2019) in sport and everyday life. In essence, a triangle made up of parents, coaches, and athletes play a crucial role in athletes' lives. All actors must know their roles, duties, and responsibilities to adequately develop athletes' personalities (Bačanac et al., 2009). Finally, these socialization processes usually happen without children's awareness (Huesmann \& Taylor, 2006).

The data contributes a more straightforward explanation and understanding of the period and the location where the children are supposed to be aggressive to others. In most cases, aggression appears after training (19.1\%), which is in line with athletes' reports about the most commonplace for these destructive behaviors as a dressing room $(28 \%)$. The idea behind this data is that after competition or training, athletes are under the influence of the events, and they can get free from the accumulated frustration without punishment from parents or coaches (Milovanović et al., 2020b; Milovanović et al., 2019b). A challenging situation can be traveling to competitions, sports camps, etc. (16.6\%) for aggressive and violent behavior. However, those athletes are "gifted" because they are selected based on their performance to go to the competition. Other children, who have less motor skill for that sport or are less talented, they only participated in the training. Nevertheless, the selection can be based on athlete behavior. If the child is very problematic, in some cases, the child will leave out for the competition or even leave the sport (Milovanović et al., 2019b).

By considering the forms of violence that can occur hypothetically based on the athletes' opinion, psychological violence is prevalent (49.6\%). In addition, the most common form of violence that has occurred is also psychological (42.3\%) based on the answers. This type of violence (verbally) has higher attention and hurts more individuals (Milovanović et al., 2019a), with emotional consequences. Physical violence is present, but in a less frequency (36.7\% in theory, $29.3 \%$ in practice).

Contrary to the findings of previous compatible research (Milovanović et al., 2020b), this research did not find statistical differences in the occurrence of violent and aggressive behavior between genders. However, in most cases, the gender difference is controversial (Wang et al., 2015). Furthermore, looking at the age categories, older school-age children tend to behave more violent than their younger peers. Assessing the results, only significant differences are present in sexual violence $(\mathrm{U}=6882.5, \mathrm{p}=0.031)$ between these two categories. Adolescents changing behavior tendencies can be the consequence of their life period, which characterized an intense development.

When it comes to the sport type, the occurrence of violence is more extensive in collective sports than in individuals one. They significantly differ in physical $(\mathrm{U}=6166, \mathrm{p}=0.004)$ and psychological $(\mathrm{U}=6692.5, \mathrm{p}=0.44)$ violence that can occur, as well in physical $(\mathrm{U}=5577, \mathrm{p}=0.00)$ and psychological $(\mathrm{U}=6557, \mathrm{p}=0.30)$ violence that occurred most frequently among athletes in the sports environment. Possible cause of this intergroup violence could be that group members are taught to solve group conflict violently (DeWall et al., 2011).

To sum up, the analyses support our hypothesis that in the sports domain in Subotica, some type of aggression and violence is present among the athletes.

\subsection{Limitations}

This research obtained an initial insight into the presence, manifestation forms of interpersonal aggression and violence in the sports clubs in Subotica, and their limitations must be addressed. The research process was made difficult by the COVID-19 pandemic, which was related to the closed gyms until the autumn or even further; fewer athletes at the sports clubs; the researchers cannot survey the respondents themselves before, during, or after training because they had to give the questionnaire papers to coaches' or to parents, who helped the athletes across the filling process of the survey. Further research should include an equal number of athletes representing each sport. Moreover, the examination of aggression and peer violence could be spread in more types of sports activities in Subotica, which may influence different results.

\section{Acknowledgment}

The data used in this study were collected within the research project called "Peer Violence in children and youth sports" (register number: 142-451-2573/2019-01), which was conducted by the Faculty of Sport and Physical Education, University of Novi Sad and financed by the Provincial Secretariat for higher education and scientific research. 


\section{Conflict of Interest}

The authors reported no conflict of interest.

\section{References}

Allen, J. J., \& Anderson, C. A. (2017). Aggression and violence: Definitions and distinctions. In P. Sturmey (Ed.), The Wiley handbook of violence (pp. 1-14).

Anderson, C. A., \& Bushman, B. J. (2002). Human aggression. Annual Review of Psychology, 53(1), $27-51$. doi:10.1146/annurev.psych.53.100901.135231

Bačanac, L., Petrović, N., \&Manojlović, N. (2009). Priručnik za roditelje mladihs sportista. Beograd: Republički zavod za sport.

Bailey, R. (2006). Physical education and sport in schools: A review of benefits and outcomes. Journal of School Health, 76(8), 397-401.

Bandura, A. (1973). Aggression: A social learning theory analysis. Englewood Cliffs, NJ: Prentice Hall.

Biddle, S. (1995). Exercise and psychosocial health. Research Quarterly for Exercise and Sport, 66(4), 292-297. doi:10.1080/02701367.1995.10607914

Bojanić, Ž., Šakan, D., \& Nedeljković, J. (2018). Personality traits as predictors of perfectionism. Facta Universitatis, 16(1), 057-071. doi:10.22190/FUPES180515006B

Brackenridge, C., Fasting, K., Kirby, S., \& Leahy, T. (2010). Protecting children from violence in sport: A review with a focus on industrialized countries: UNICEF Innocenti Research Centre.

Bushman, B. J., \& Huesmann, L. R. (2010). Aggression. In S. T. Fiske, D. T. Gilbert, \& G. Lindzey (Eds.), Handbook of Social Psychology (5 ed., Vol. 2). Hoboken, NJ: John Wiley \& Sons.

Collins, N. M., Cromartie, F., Butler, S., \& Bae, J. (2018). Effects of Early Sport Participation on Self-esteem and Happiness. The Sport Journal, 20, 1-20.

DeWall, C. N., Anderson, C. A., \& Bushman, B. (2011). The General Aggression Model: Theoretical Extensions to Violence. Psychology of Violence, 1(3), 245. doi:10.1037/a0023842

Gentile, A., Milovanović, I., Valantine, I., Kreivyte, R., Tilindiene, I., Mujkić, D., ... Drid, P. (2019). Violence, exclusion and the role of children and adolescents moral features in the sport domain: The save project. Acta Medica Mediterranea, 35, 1681.doi:10.19193/0393-6384_2019_3_263

Huesmann, L. R., \& Taylor, L. D. (2006). The role of media violence in violent behavior. Annual Review of Public Health, 27, 393-415. doi:10.1146/annurev.publhealth.26.021304.144640

Koo, J.-E., \& Lee, K.-U. (2014). The relationships of elementary school students' sports participation with optimism, humor styles, and school life satisfaction. Journal of Exercise Rehabilitation, 10(2), 111. doi: $10.12965 /$ jer. 140093

Liu, J. (2004). Concept analysis: aggression. Issues in Mental Health Nursing, 25(7), 693-714. doi:10.1080/01612840490486755

Milovanović, I., Gentile, A., Gutović, T., Kezić, A., Matošić, D., Kreivytė, R., ... Drid, P. (2020a). Prosocial and Aggressive Behavior Occurrence in Young Athletes: Field Research Results in Six European Countries. Sustainability, 12(12), 5085. doi:10.3390/su12125085

Milovanović, I., Matić, R., Vuković, J., Blagojević, M., Mikić, M., \& Marinković, D. (2020b). Towards recognition of peer violence in youth sports-the case of Vojvodina. Exercise and Quality of Life, 12(1), 21-28. doi:10.31382/eqol.200603

Milovanović, I., Milošević, Z., Maksimović, N., Korovljev, D., \& Drid, P. (2019a). Certain Indicators of Violence in Children and Youth Sports. Physical education and sport through the centuries, 6(2), 46-61. doi:10.2478/spes- 2019- 0012

Milovanović, I., Roklicer, R., \& Drid, P. (2019b). The Relation between Youth sport and the Reduction of Peer Violence. Facta Universitatis, 17(3), 479-490. doi:10.22190/FUPES190413042M

Park, S., Chiu, W., \& Won, D. (2017). Effects of physical education, extracurricular sports activities, and leisure satisfaction on adolescent aggressive behavior: A latent growth modeling approach. PloS One, 12(4), e0174674. doi:10.1371/journal.pone.0174674

Popadić, D. (2009). Nasilje u školama (School Violence). Belgrade: Institute of Psychology.

Radenović, S. (2012). Bioetika i nasilje. JAHR, Annual of the Department of Social Sciences and Medical Humanities University of Rijeka School of Medicine, 3(1), 205-218.

Richman, E. L., \& Shaffer, D. R. (2000). "IF YOU LET ME PLAY SPORTS" How Might Sport Participation Influence the Self- Esteem of Adolescent Females? Psychology of Women Quarterly, 24(2), 189-199. doi:10.1037/cjbs2006009

Steptoe, A., \& Butler, N. (1996). Sports participation and emotional wellbeing in adolescents. The Lancet, 347(9018), 1789-1792. doi:10.1016/S0140-6736(96)91616-5

Stoeber, J. (2014). Perfectionism in sport and dance: A double-edged sword. International Journal of Sport Psychology, 45(4), 385-394. 
Tripković, M. (2007). Nasilje. In A. Mimica \& M. Bogdanović (Eds.), Sociološki rečnik (pp. 346-347). Beograd: Zavod za udžbenike.

Wang, S., Zhang, W., Li, D., Yu, C., Zhen, S., \& Huang, S. (2015). Forms of aggression, peer relationships, and relational victimization among Chinese adolescent girls and boys: roles of prosocial behavior. Frontiers in Psychology, 6, 1264. doi:10.3389/fpsyg.2015.01264

Wankel, L. M., \& Berger, B. G. (1990). The Psychological and Social Benefits of Sport and Physical Activity. Journal of Leisure Research, 22(2), 167-182.

Williams, Y. (2011). Protecting children from violence in sport: a Unicef Report. ESLJ, 9, 72.

Živković, M., Stamenković, M., \& Marković, M. (2013). Violence in sport and its perpetrators in modern society TEME: Časopis za društvene nauke, 37(2), 939-952. 